\title{
mRNA-Seq reveals the quorum sensing system luxS gene contributes to the environmental fitness of Streptococcus suis type 2
}

Jinpeng Li $i^{1,2 \dagger}$, Yuxin Wang ${ }^{1,2+}$, Yanbin Du ${ }^{1,2}$, Hui Zhang ${ }^{3}$, Qingying Fan ${ }^{1,2}$, Liyun Sun ${ }^{1,2}$, Li Yi $^{4}$, Shaohui Wang ${ }^{5^{*}}$ and Yang Wang ${ }^{1,2^{*}}$

\begin{abstract}
Background: Streptococcus suis type 2 (SS2) is an important zoonotic pathogen. We have previously reported the structure of LuxS protein and found that the luxS gene is closely related to biofilm, virulence gene expression and drug resistance of SS2. However, the mechanism of luxS mediated SS2 stress response is unclear. Therefore, this experiment performed stress response to luxS mutant $(\Delta / \mathrm{u} S \mathrm{~S})$ and complement strain (C$\Delta / \mathrm{u} X S)$, overexpression strain (luxS+) and wild-type SS2 strain HA9801, and analyzed the differential phenotypes in combination with transcriptome data.

Results: The results indicate that the luxS gene deletion causes a wide range of phenotypic changes, including chain length. RNA sequencing identified $278 / x$-regulated genes, of which 179 were up-regulated and 99 were down-regulated. Differential genes focus on bacterial growth, stress response, metabolic mechanisms and drug tolerance. Multiple mitotic genes were down-regulated; while the $A B C$ transporter system genes, cobalamin $/ \mathrm{Fe}^{3+}{ }_{-}$ iron carrier ABC transporter ATPase and oxidative stress regulators were up-regulated. The inactivation of the luxS gene caused a significant reduction in the growth and survival in the acid $(\mathrm{pH}=3.0,4.0,5.0)$ and iron (100 mM iron chelator 2,2'-dipyridyl) stress environments. However, the mutant strain $\Delta /$ uxS showed increased antioxidant activity to $\mathrm{H}_{2} \mathrm{O}_{2}(58.8 \mathrm{mmol} / \mathrm{L})$.
\end{abstract}

Conclusions: The luxS gene in SS2 appears to play roles in iron metabolism and protective responses to acidic and oxidative environmental conditions.

Keywords: Streptococcus suis, luxS gene, Acid resistance, Iron stress, Oxidative stress

\footnotetext{
*Correspondence: shwang0827@126.com; wangyocean@163.com

${ }^{\dagger}$ Jinpeng Li and Yuxin Wang contributed equally to this work.

${ }^{5}$ Shanghai Veterinary Research Institute, Chinese Academy of Agricultural Sciences, Shanghai, China

${ }^{1}$ College of Animal Science and Technology, Henan University of Science and Technology, Luoyang, China

Full list of author information is available at the end of the article
}

(C) The Author(s). 2021 Open Access This article is licensed under a Creative Commons Attribution 4.0 International License, which permits use, sharing, adaptation, distribution and reproduction in any medium or format, as long as you give appropriate credit to the original author(s) and the source, provide a link to the Creative Commons licence, and indicate if changes were made. The images or other third party material in this article are included in the article's Creative Commons licence, unless indicated otherwise in a credit line to the material. If material is not included in the article's Creative Commons licence and your intended use is not permitted by statutory regulation or exceeds the permitted use, you will need to obtain permission directly from the copyright holder. To view a copy of this licence, visit http://creativecommons.org/licenses/by/4.0/ The Creative Commons Public Domain Dedication waiver (http://creativecommons.org/publicdomain/zero/1.0/) applies to the data made available in this article, unless otherwise stated in a credit line to the data. 


\section{Background}

Streptococcus suis (SS) is a major pathogen in pigs, and it is also a zoonotic agent of a variety of diseases for swine and humans. Among the thirty-three serotypes of SS (serotypes 1-32 and serotype 1/2), Streptococcus suis serotype 2 (SS2) are generally considered to be the most virulent serotypes found so far. It can cause a variety of life-threatening infections, including meningitis, arthritis and sepsis $[1,2]$. The LuxS/AI-2 quorum sensing (QS) system is considered a process by which bacteria communicate using autoinducers 2 (AI-2). It is widespread in Gram-positive and Gram-negative bacteria. LuxSmediated QS mechanism is based on the production of AI-2 that regulates various important biological properties in different bacteria [3]. In our previous study, we have shown that the loss of luxS gene can reduce the biofilm formation ability, hemolytic activity, adhesion to human laryngeal carcinoma (HEp-2) cell line and virulence genes transcription, and the luxS gene also related to drug-resistant efflux gene expression of SS [4-7]. Furthermore, our research found that $\operatorname{luxS}$ gene can regulate $p d h$ genes that affect acid stress and oxidative stress of S. suis [8]. The ability of bacteria to resist environmental stress is one of the important factors for their survival. Studies have shown that LuxS protein is involved in regulating changes in bacterial resistance to stress [9]. However, the relevant mechanisms remain unclear.
The quorum sensing system is an important protective mechanism for bacteria to adapt to the environment [3, 10]. Previous studies have shown that luxS and AI-2 involved in bacterial regulation of a series of important stress responses, including heat shock, anti-gamma radiation, $\mathrm{H}_{2} \mathrm{O}_{2}$ and other oxidative stress responses [11-15]. With the deepening of $\operatorname{luxS}$ research, researchers found that $\operatorname{luxS}$ showed different phenotypes in some bacteria after mutation. For example, the luxS mutation in Helicobacter pylori leads to a decrease in the expression of flagella transcription regulator $f l h A$ and a decrease in motility [16]. Compared with the wild-type strain, the luxS mutant of Escherichia coli has increased survival in the environment with $\mathrm{pH}<3.2$ [17]. In addition, the $\mathrm{ABC}$ transporter gene of radiation Deinococcus radiodrans luxS mutant is up-regulated under oxidative stress, and $A B C$ transporter participates in the adaptation mechanism of stress environment, transporting damaged nucleotides and polypeptides to vitro. And it's proved that the luxS mutant of Borrelia burgdorferi has reduced pathogenicity in mice [18]. Moreover, Liu et al. found that overexpression of luxS gene could improve the stress resistance of Lactobacillus paraplantarum L-ZS9 [9]. We have found luxS gene as an important regulator in many aspects [10]. However, it is still unknown that the impact of the luxS genes on SS growth and stress responses. In order to
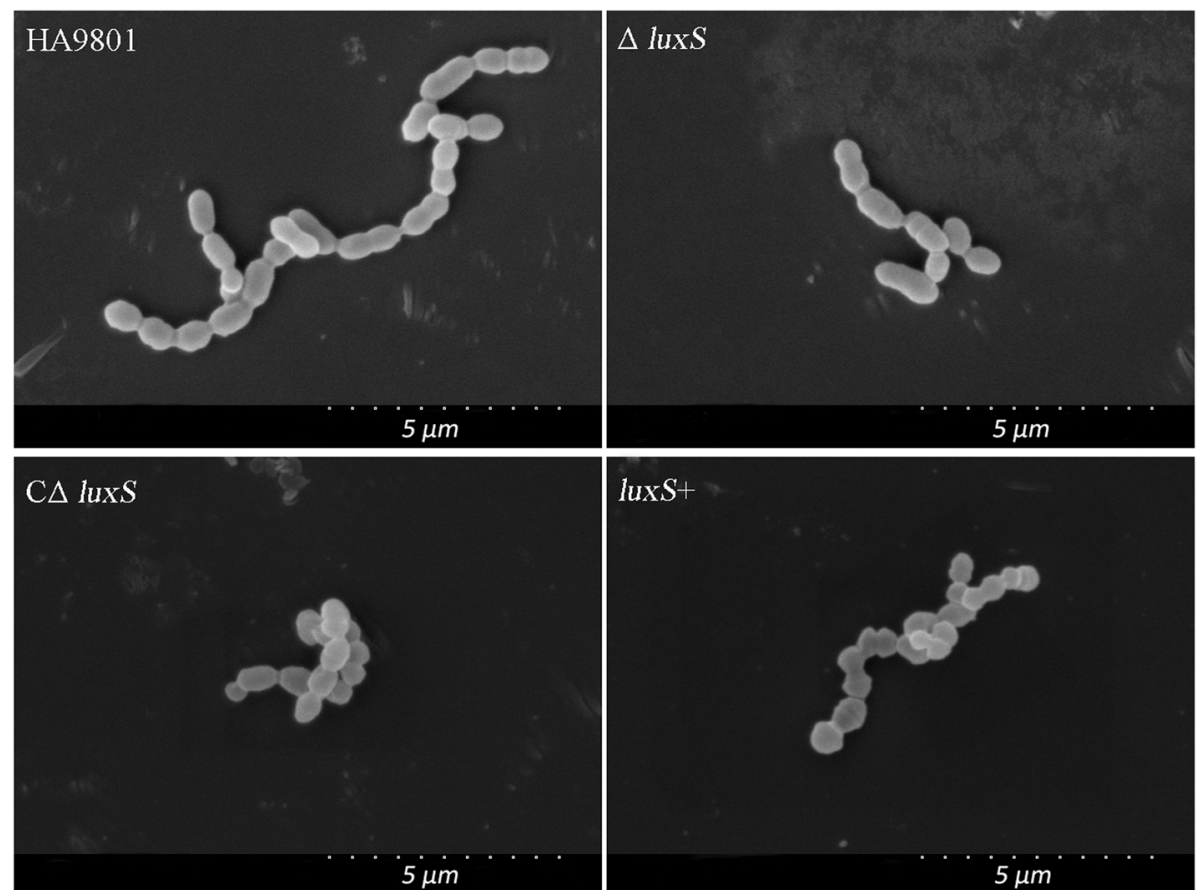

Fig. 1 The morphology of SS2 wild-type strain HA9801, mutant strain $\Delta / \mathrm{uxS}$ complemented strain C $\Delta /$ /uxS and overexpression strain luxS+ under SEM 
understand the $\operatorname{luxS}$ gene more fully, in this study, we wanted to know the differences of wild-type strain, $\Delta l u x S, C \Delta l u x S$ and $l u x S+$ in growth characteristics and stress responses.

\section{Results}

\section{Cell morphology}

Through SEM observations, mutant strain $\Delta l u x S$ tended to grow in chain length and exhibited abnormal morphology relative to the wild-type strain (Fig. 1). In addition, the aggregation ability of $\Delta l u x S$ cells was significantly weaker than that of wild-type strain (Fig. S1). These morphology phenotypes can be restored in part by $C \Delta$ luxS. However, the differences between the overexpression strain luxS+ and wild-type strain were not significant. Gram stain results showed that the morphological characteristics of the four strains consistent with the results of SEM (data not shown).

\section{Growth curves}

The growth curves of wild-type, $\Delta l u x S, C \Delta l u x S$ and luxS+ SS2 strains are presented in Fig. S2 (Supplementary material). Compared with the wild-type strain, the mutant strain $\Delta l u x S$ did not show growth defects. For complementary strains, the difference between $\mathrm{C} \Delta l u x S$ and overexpression strain $\operatorname{lu} x S_{+}$is not significant $(P>0.05)$.
$\Delta$ luxS mutant and wild-type strain transcriptome analysis Analysis of transcriptome data shows that $\operatorname{luxS}$ gene mutation has a wide-ranging effect on the gene expression of SS. There were 1978 identically expressed genes in the SS wild-type strain and the mutant strain $\Delta l u x S$. In addition, there were 179 up-regulated genes and 99 down-regulated genes (Table S1; Table S2, supplementary material). Obviously, the amino acid ABC transporter permease gene expression was up-regulated most and acetyltransferase gene, cell division genes was downregulated most. Gene Ontology (GO) analysis identified the biological functions of differentially expressed genes, and found that the main enrichment of differential genes was in biological processing and molecular functions. There was no significant enrichment of differential genes in cellular components, as shown in Fig. 2.

\section{qRT-PCR}

In order to verify the reliability of the RNA-seq results, 6 differentially expressed genes were randomly selected for verification (Fig. S3, supplementary material). The results showed that SSU05_2024, SSU05_1111, and SSU05_1069 were significantly up-regulated, and SSU05_0050, SSU05_0087, and SSU05_0302 were significantly down-regulated. The above results are consistent with the RNA-seq results $(P>0.05)$, indicating the reliable of transcriptome results. In addition, qRT-PCR

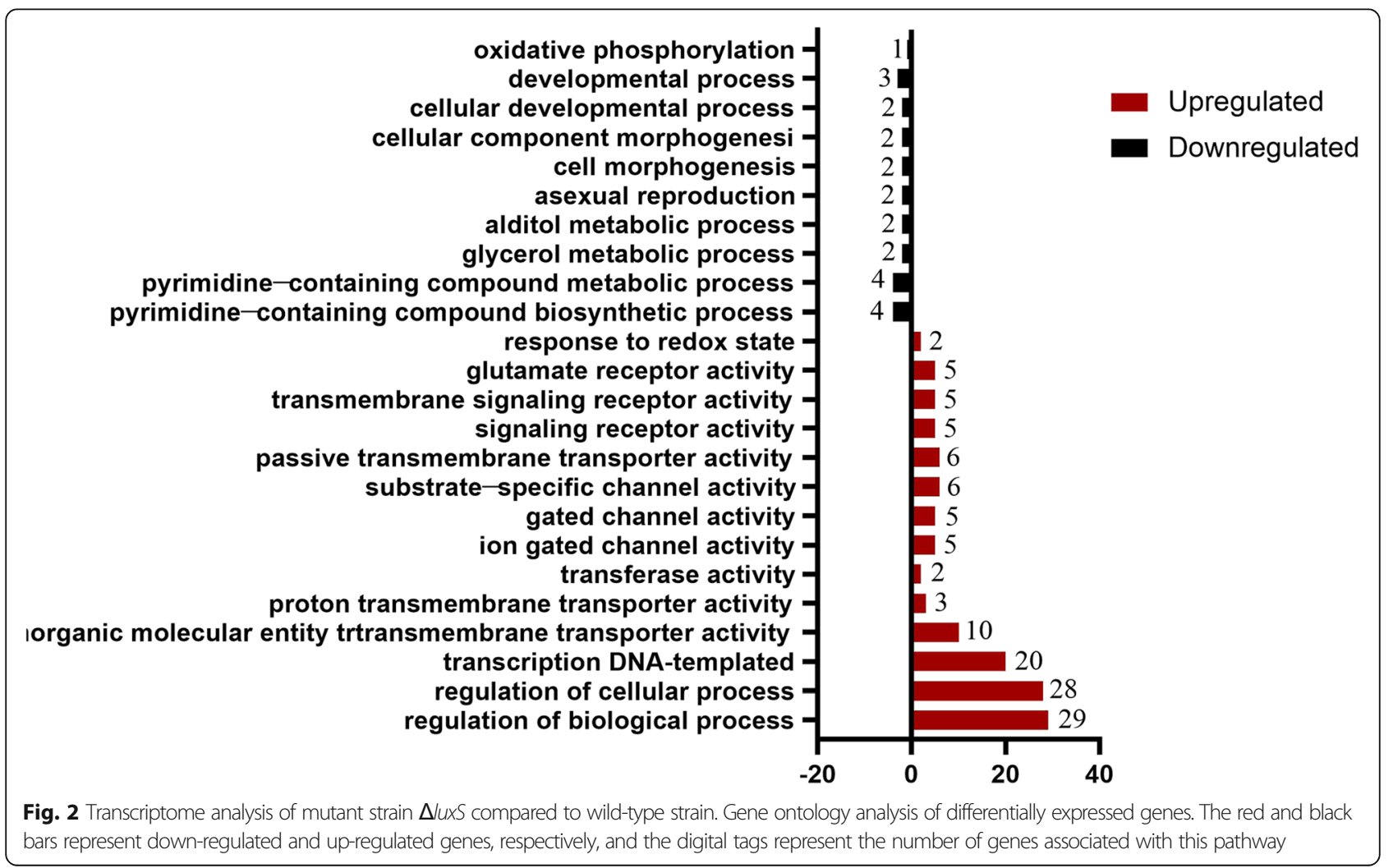


analysis was performed to compare WT, $\Delta l u x S, C \Delta l u x S$ and $l u x S+$ strains for the expression of several genes involved in environmental fitness. The expression of SSU05_1677, SSU05_0650, SSU05_2171, SSU05_1508 was significantly $(p<0.01)$ decreased and SSU05_1111, SSU05_1069 was significantly increased (Fig. S4). There was no significant difference between the WT, and $\mathrm{C} \Delta \operatorname{luxS}$ and $l u x S+$.

\section{Acid tolerance of SS}

The acid tolerance assay suggested that four strains (HA9801, $\Delta l u x S, C \Delta l u x S$, and $l u x S+$ ) viability decreased with $\mathrm{pH}$ value of the medium. Wherein, compared with $\mathrm{pH}$ values of 5.0,6.0, 7.0, the $\mathrm{OD}_{600 \mathrm{~nm}}$ values of the four strains at $\mathrm{pH}=3.0$ and $\mathrm{pH}=4.0$ decreased significantly. In addition, there is no difference in growth status among the HA9801, C $\Delta l u x S$, and $l u x S+$ strains in acidic environments. However, the mutant strain $\Delta l u x S$ showed significantly decreased survival $(P<0.05)$ in acidic environments ranging from $\mathrm{pH} 3.0$ to $\mathrm{pH} 5.0$ at tested times compared with wild-type strain (Fig. 3), and the viable count of $\Delta$ luxS was lower than that of WT at PH = 5 for $12 \mathrm{~h}$ or $24 \mathrm{~h}(P<0.001)$. Moreover, complementation of luxS gene restored the acid resistance for the complemented strain $(P>0.05)$. These results indicated that $l u x S$ gene contributed to the acid tolerance of SS2.

\section{Fe stress response}

The effects of exogenous $\mathrm{Fe}^{2+}$ and $\mathrm{Fe}^{3+}$ on the growth of SS were determined. It was observed that wild-type and luxS+ strains, in the presence of $3 \mathrm{mmol} / \mathrm{L}$ iron chelator were not significantly impacted by the metabolic stressor $(P>0.05)$ at $6 \mathrm{~h}$ or $12 \mathrm{~h}$. However, mutant strain $\Delta l u x S$ was observed to have a significantly reduced $\mathrm{OD}_{600 \mathrm{~nm}}$ value $(P<0.001)$ compared with wild-type strain. Moreover, the growth capacity of $\mathrm{C} \Delta l u x S$ was retored by the $\operatorname{luxS}$ gene complementation. The effect of $\mathrm{Fe}^{2+}$ on the growth of $\Delta l u x S$ was more pronounced than that of $\mathrm{Fe}^{3+}$ (Fig. 4).

\section{Oxidative stress response}

To assess the capability of the luxS gene to manage oxidative stresses, survival of the SS2 wild-type, $\Delta l u x S$, $C \Delta l u x S$ and $l u x S+$ strains were measured after $1 \mathrm{~h}, 2 \mathrm{~h}$, $3 \mathrm{~h}$ or $4 \mathrm{~h}$ of $\mathrm{H}_{2} \mathrm{O}_{2}$ treatment. The results indicated that the wild-type strain were more susceptible to $\mathrm{H}_{2} \mathrm{O}_{2}$ treatment $(58.8 \mathrm{mmol} / \mathrm{L})$ than the mutant strain $\Delta l u x S$. Survival rate of the $C \Delta l u x S$ and wild-type strains were significantly different from that of $\Delta l u x S(P<0.05)$, and it was very significant with $l u x S+$ strain $(P<0.01)$. Therefore, it can be concluded that $\operatorname{luxS}$ is associated with the antioxidant activity of SS2 (Fig. 5).

\section{Discussion}

The highly conserved $\operatorname{luxS}$ gene has been extensively studied in recent years due to its involvement in the regulation of the expression of various growth and virulence-related genes $[19,20]$. The related AI-2 is a compound that plays a key role in bacterial cell-to-cell communication [21]. In this study, we compared the cell morphology and response of mutant strain $\Delta l u x S$ and wild-type strain HA9801 to different stress conditions.
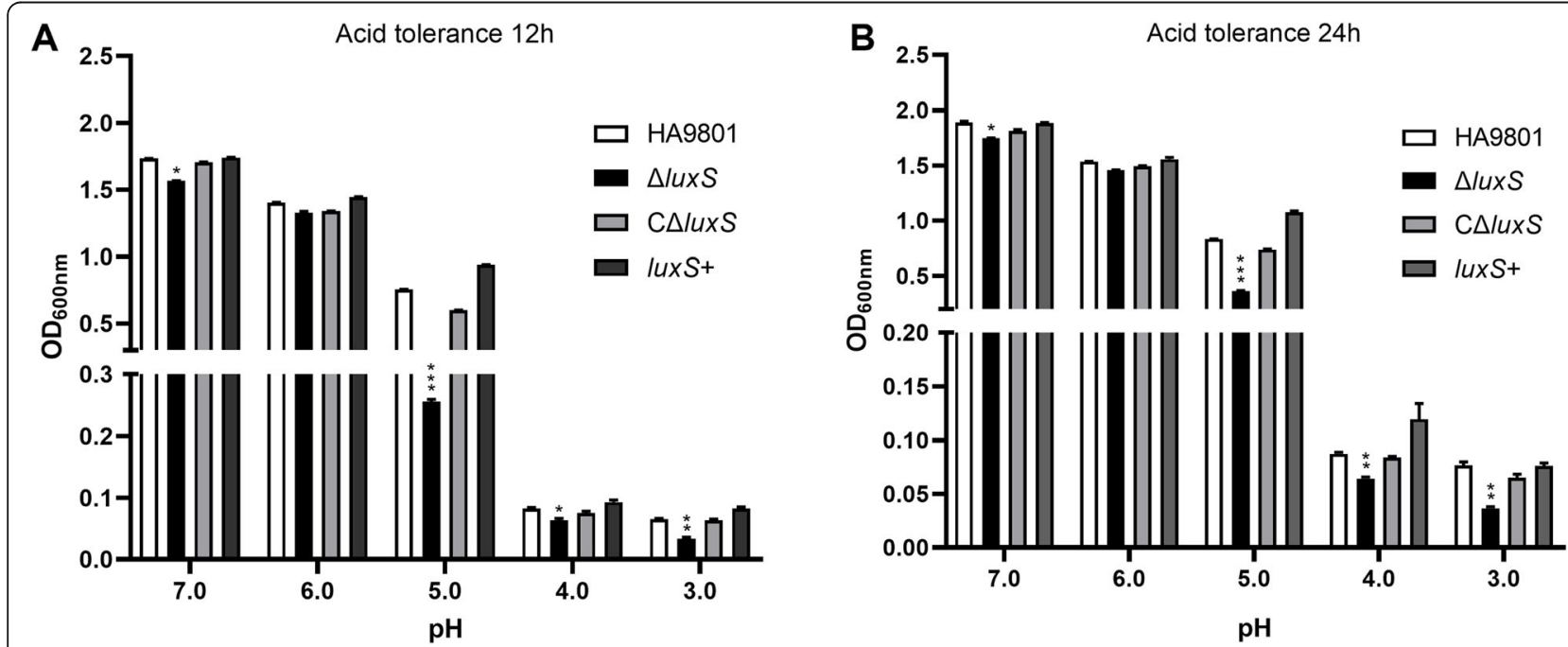

Fig. 3 Acid resistance trends of SS2 strains at 12 and $24 \mathrm{~h}$. The SS2 bacterial suspension was inoculated in THB liquid medium with pH values of 3.0, 4.0, 5.0, 6.0, 7.0 (adjusted with $6 \mathrm{~N} \mathrm{HCl}$ ), and the growth of each strain was measured at $12 \mathrm{~h}$ and $24 \mathrm{~h}$. The growth and survival of mutant strain $\Delta /$ UXS was significantly decreased in $\mathrm{pH} 3.0,4.0$ and 5.0 acidic environments compared with wild-type and complemented strain. The columns express the means and standard deviations of three or more experiments. ${ }^{*}$, significantly different at $p<0.05$; ${ }^{*}$, significantly different at $p<0.01 ;{ }^{* *}$, significantly different at $p<0.001$ 


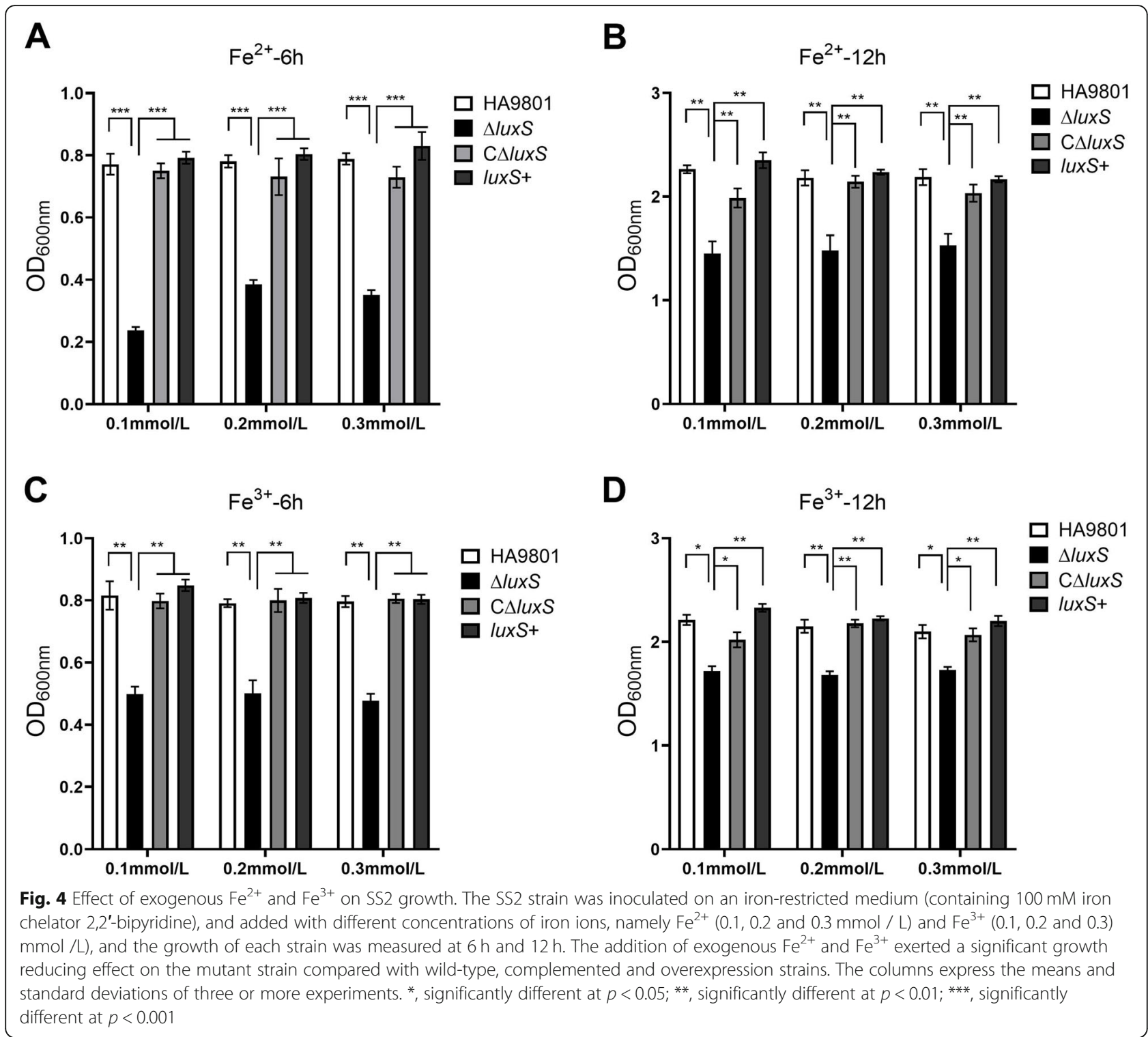

The transcriptome differences between HA9801 and $\Delta l u x S$ were also determined. Our results showed that mutant strain $\Delta l u x S$ showed a large transcriptional difference and significantly different tolerance to stress environments.

We found that the growth rate of mutant strain $\Delta l u x S$ was similar with those of wild-type, C $\Delta l u x S$ and $l u x S+$ strains. This experimental results corroborate the findings of Zhang et al. [22] and Van et al. [23], in which the absence or overexpression of the luxS gene no affecting the expression of other downstream genes important for bacterial growth. Previous studies also reported that luxS + did not increase the level of AI-2 production, and no affected the growth of SS [1].

Acid resistance is a necessary for bacterial survival in acidic environments and during infection of the host through the digestive tract. In the present experiment, the acid stress test revealed an overall downward trend in vitality in acidic environmental conditions. The downward trend of $\Delta l u x S$ was more pronounced than that of wild-type strain, and the viability decreased precipitously when the $\mathrm{pH}<5.0$. Acid stress on $l u x S+$ showed slightly stronger acid resistance than wild-type strain. The loss of the luxS gene results in many altered traits, including thinning of the bacterial capsule, which may be a cause of the altered acid resistance. In addition, with the down-regulated of the cell division protein genes SSU05_0760 and SSU05_0761, the $\Delta l u x S$ strain showed abnormal cell chains. The results were similar to Cao et al. [24]. At same, previous studies have also found that luxS gene is involved in biofilm formation [10]. At $\mathrm{pH}=$ 3.0, the wild-type and $\Delta l u x S$ strains had not yet been 


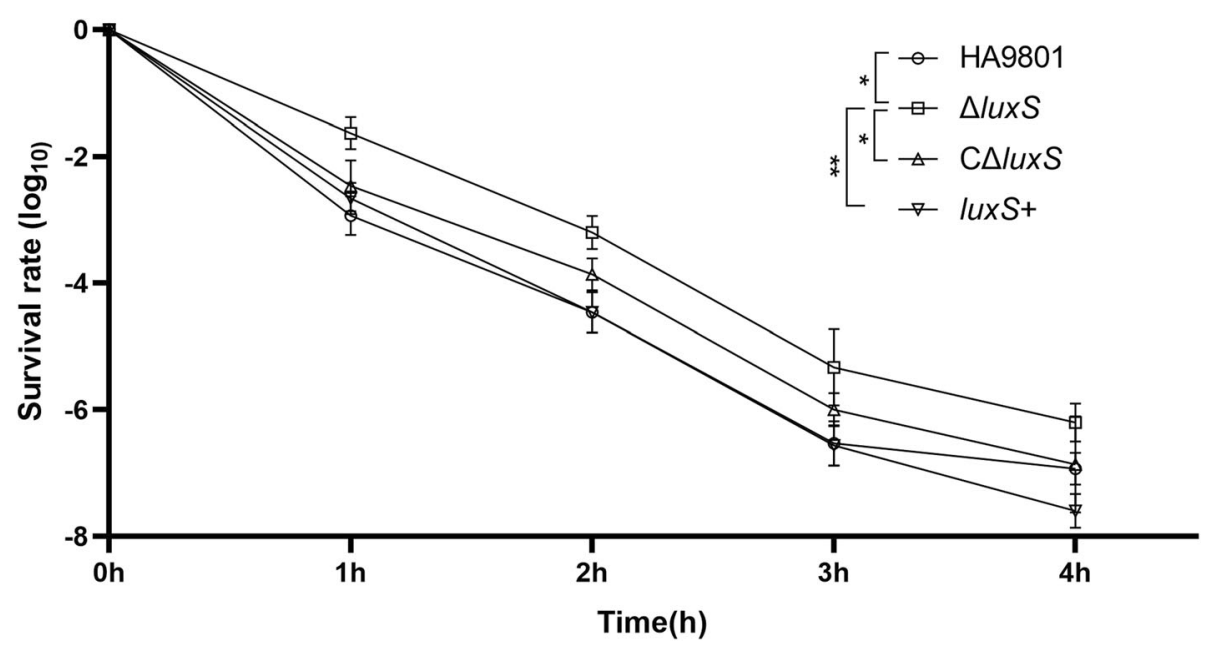

Fig. 5 Survival rates of SS2 strains under oxidative stress. The SS2 strains were inoculated at medium containing $58.8 \mathrm{mmol} / \mathrm{L} \mathrm{H}_{2} \mathrm{O}_{2}$, and the survival of each strain was measured at indicated time. The survival rate of mutant strain $\Delta / \mathrm{u} S \mathrm{~S}$ was higher than those of the wild-type strain, $C \Delta / \mathrm{uxS}$ and luxS+ at 1 h, 2 h, 3 h or $4 \mathrm{~h} .{ }^{*}$, significantly different at $p<0.05$; ${ }^{* *}$, significantly different at $p<0.01$; ${ }^{* *}$, significantly different at $p<0.001$

completely killed, suggesting that the $\operatorname{luxS}$ gene is part of a redundant system through which SS2 creates its acid resistance. These observation suggest that acid regulation is a complex process that may be influenced through a variety of regulatory pathways [25], the SS2 luxS gene appears to be part of one such regulatory pathway.

Iron is actually an essential element in all cells because iron is a cofactor in many enzymes, especially central metabolism and respiratory enzymes, so it is a coenzyme. Wen et al. [26] found that the growth inhibition of $\Delta l u x S$ in the medium containing $0.3 \mathrm{mmol} / \mathrm{L} 2,2^{\prime}$ bipyridine was alleviated by adding exogenous iron and culture supernatant regulated by wild-type strains. In addition, Lee et al. [27] used to the gene chip to analyze and compare the transcription data of wild-type and mutant $\Delta l u x S$ strains of Streptococcus pneumoniae at 4 different growth phages. It was found that two TonB systems are involved in iron absorption. Furthermore, tonB1-exbB1-exbD1 and tonB2-exbB2-exbD2 are affected by the luxS gene in all four growth stages [28]. Although nature is rich in iron, it is easily oxidized to insoluble matter, so the iron available to bacteria is scarce. Moreover, the easily soluble Fe tends to react with oxygen to produce reactive oxygen intermediates and affect the physiological processes of bacteria. Therefore, for S. suis, it is necessary to suppress the harmful effects of $\mathrm{Fe}$ and to store the excess $\mathrm{Fe}$ in a removable form. So iron transportability is very important. In the present study, the results showed that the addition of exogenous $\mathrm{Fe}^{2+}$ resulted in reduced growth of the wildtype strain with increasing ion concentration at $6 \mathrm{~h}$ and $12 \mathrm{~h}$. The effects caused by $\mathrm{Fe}^{3+}$ were more pronounced than those of $\mathrm{Fe}^{2+}$ on growth promotion of the $\Delta l u x S$ mutant strain, although the difference was not significant $(P>0.05)$. There was no significant difference observed in the growth status between wild-type and $l u x S+$ strains $(P>0.05)$. In comparison to the wild-type and luxS+ strains, the growth of the $\Delta l u x S$ mutant was observed to be significantly decreased $(P<0.001)$. The growth ability $C \Delta l u x S$ did recover, albeit not to the level of the wild-type strain. Besides, in the mutant strain, the expression of the cobalamin / $\mathrm{Fe}^{3+}$-iron carrier $\mathrm{ABC}$ transporter ATPase gene SSU05_0650 was up-regulated, up to 1.976 times. We speculate that the reason why the mutant strain is more sensitive to $\mathrm{Fe}^{2+}$ than $\mathrm{Fe}^{3+}$ in the experiment may be due to the enhanced ability of the mutant strain to transport $\mathrm{Fe}^{3+}$ ions [29]. Taken together, the data suggest that the $\operatorname{luxS}$ gene is involved in SS iron absorption, and the regulation of bacterial growth.

Oxidative stress is one defense mechanism of the host against an invading pathogen. Bacterial infections must first overcome the host's stress defense mechanism. Yu et al. [30] knocked out the luxS gene of Yersinia pestis, and observed that the mutant exhibited a reduced resistance to $\mathrm{H}_{2} \mathrm{O}_{2}$. However, the Porphyromonas gingivalis $\Delta l u x S$ strain exhibited increased survival in the presence of $\mathrm{H}_{2} \mathrm{O}_{2}$ [31], this finding is similar to what was previously reported by Cao et al. [24] with respect to a $\mathrm{H}_{2} \mathrm{O}_{2}$ stress test of $\triangle l u x S$ of SS2 strain 05ZYH33. The results of this experiment showed that mutant strain $\Delta l u x S$ were more tolerant to $\mathrm{H}_{2} \mathrm{O}_{2}$ than the wild-type strain. This suggests that $l u x S$ genes have different roles in different bacterial species. After analyzing comprehensive transcriptome data, we believe that the differences in stress resistance of $\Delta l u x S$ and wild-type strains may result in phenotypic differences due to the abnormal 
transcription of some genes after the luxS gene is mutant. Transcriptome data showed that the SS spxA transcriptional regulator SSU05_1111 and the possible oxidative stress-related gene SSU05_1069 were found in $\triangle l u x S$ strains, and their expressions were up-regulated by 2.5 and 2.1 fold, respectively. It has a certain tolerance to $\mathrm{H}_{2} \mathrm{O}_{2}$ compared with the wild strain; research shows that $s p x A$ transcriptional regulators play an important role in oxidative stress response of SS. spxA mutant strains are more sensitive to the oxidative environment of SS [32, 33].

\section{Conclusion}

In summary, the results presented here clearly demonstrate that there is a transcriptional difference between the SS2 WT strain and the $\Delta l u x S$ strain. We also proved that the quorum sensing system $\operatorname{luxS}$ gene is of great significance to the morphological structure as well as stress resistance of SS2.

\section{Materials and methods \\ Bacterial strain and culture conditions}

Four S. suis strains were used in this study: the SS2 virulent wild-type strain HA9801 was isolated from pigs in the Jiangsu Province in 1998, and its mutant strain $\Delta l u x S$, complemented strain $C \Delta l u x S$, overexpression strain luxS+ of HA9801 was constructed in our previous study $[1,2]$. The above four strains were preserved in our laboratory, and we verified the four strains by PCR before tests to ensure the correctness. The SS strains were grown at $37^{\circ} \mathrm{C}$ in Todd Hewitt broth (THB) (Becton, Dickinson and Company, USA) medium or plated on THB agar with 5\% (vol/vol) sheep blood (Becton, Dickinson and Company, USA).

\section{Morphological characteristics}

The morphological differences were determined by scanning electron microscopy according to the method previously described [34]. Briefly, coverslips with SS2 cultures were rinsed 3 times with a phosphate buffered solution (Sigma-Aldrich, USA). The samples were then post-fixed for $90 \mathrm{~min}$ with $1 \%(\mathrm{w} / \mathrm{v})$ osmium tetroxide (Hubei Baizhiang Biochemical Co., Ltd., China) in a 0.1 $M$ sodium cacodylate buffer (Shanghai Xinyu Biological Technology Co., Ltd., China). After staining, the specimens were dehydrated in increasing concentrations of acetone (Shanghai Xinyu Biological Technology Co., Ltd., China) $(10,30,50,70,90$, and 100\%). The specimens were then air-dried for $60 \mathrm{~min}$, and were then adhered to metal holders with double-sided tape for coating with gold and palladium in an evaporator. All specimens were positioned with the apices facing up for proper visualization by scanning electron microscopy $(\mathrm{SEM})$ in a vacuum at $5 \mathrm{kV}$ electron beam energy
(Hitachi S4700 FESEM; Hitachi Ltd., Tokyo, Japan). The bacterial morphology was also observed by gram staining and optical microscope (OM).

\section{Growth curve}

The logarithmic growth phase SS2 cultures were diluted 1: 200 to achieve an optical density at $600 \mathrm{~nm}\left(\mathrm{OD}_{600 \mathrm{~nm}}\right)$ of approximately 0.05 . These cultures were incubated at a constant temperature shaking incubator at $37^{\circ} \mathrm{C}$, shaking at $120 \mathrm{rpm}$. The $\mathrm{OD}_{600 \mathrm{~nm}}$ values of the cultures were measured at $1 \mathrm{~h}$ interval using a spectrophotometer.

\section{RNA-seq analysis}

The experimental operation was performed as previously described with minor modifications [35]. The strains SS HA9801 and $\Delta l u x S$ were cultured in THB medium for 6 $\mathrm{h}$, and harvested at $8000 \times \mathrm{g}$ at $4{ }^{\circ} \mathrm{C}$ for $10 \mathrm{~min}$. Then, the total RNA was extracted with the Trizol Reagent kit (Invitrogen, USA). Three biological replicates were set for each sample, and all samples were sent to Beijing Novogene Co., Ltd. for sequencing by Illumina Hiseq platform. Quality control was performed on the clean reads, and mapping was performed with reference to the SS 05ZYH33 genome. Gene function annotation was performed through the orthologous group (COG) database [36].

\section{Validation of mRNA-Seq by qRT-PCR}

The qRT-qPCR method was used to verify the expression results of mRNA-Seq in the transcriptome. Use Total RNA Extraction Kit (Solarbio, China) to extract total RNA, RNase-free DNase I to remove genomic DNA. The cDNA was amplified using MagicSYBR mix (CoWin Biosciences Co., Ltd., China). The volume of the amplification mixture was set to $20 \mu \mathrm{l}(2 \times$ MagicSYBR Mixture $10 \mu \mathrm{l}$, each primer of $0.5 \mu \mathrm{M}$, cDNA $1 \mu \mathrm{g}$, finally add RNase-free water to $20 \mu \mathrm{l})$. The PCR reaction conditions were as follows: at $95^{\circ} \mathrm{C}$ for $30 \mathrm{~s}$, then at $95^{\circ} \mathrm{C}$ for $5 \mathrm{~s}$, and then at $60^{\circ} \mathrm{C}$ for $30 \mathrm{~s}$ for 40 cycles. Randomly select 6 genes, and use 16S rRNA as internal reference to verify the original data. Table S3 lists all primers.

\section{Acid stress assay}

To assess the sensitivity of SS strains to acid stress conditions, we carried out an acid stress assay as previously described [37], with slight modification. Liquid THB media was prepared with $\mathrm{pH}$ values ranging from 3.0 to 7.0 (adjusted with $6 \mathrm{~N} \mathrm{HCl}$ ). Approximately $1 \sim 3 \times 10^{6}$ CFU SS2 bacterial suspension were inoculated at a ratio of $1: 10(\mathrm{v} / \mathrm{v})$ at $37^{\circ} \mathrm{C}$ for $12 \mathrm{~h}$ or $24 \mathrm{~h}$ under aerobic conditions. Growth kinetics of each strain was measured by monitoring $\mathrm{OD}_{600 \mathrm{~nm}}$ values under various conditions. 


\section{Fe stress assay}

The Fe stress response assay was performed as previously described [38], with some modifications. All strains were sub-cultured at the same original cell density from two subculture in iron restricted THB medium (containing $100 \mathrm{mM}$ iron chelator 2,2'-dipyridyl). Then, transfer all the strains (HA9801, $\Delta \operatorname{luxS}, \mathrm{C} \Delta \operatorname{lux} S,+\operatorname{lu} x S$ ) grown in iron-restricted THB medium to the same volume of fresh THB medium. Then all the strains cultures were diluted 1: $200(\mathrm{v} / \mathrm{v})$, and different concentrations of iron ions were added to THB broth, of which $\mathrm{Fe}^{2+}(0.1,0.2$ and $0.3 \mathrm{mmol} / \mathrm{L})$ and $\mathrm{Fe}^{3+}(0.1,0.2$ and $0.3 \mathrm{mmol} / \mathrm{L})$. The cultures were incubated at $37^{\circ} \mathrm{C}$ with aeration. The above cultures were incubated for $6 \mathrm{~h}$ (exponential phase) or $12 \mathrm{~h}$ (stable period), and centrifuged at 3000 rpm for $10 \mathrm{~min}$ at $4{ }^{\circ} \mathrm{C}$. The bacterial cell pellets were resuspended in the same volume of PBS buffer, and $250 \mu \mathrm{L}$ of the mixture was added to a 96-well microtiter plate. The assays were performed in triplicate and the $\mathrm{OD}_{600 n m}$ values were measured.

\section{Oxidative stress assay}

Assessment of the bacterial cells abilities to withstand $\mathrm{H}_{2} \mathrm{O}_{2}$ challenges was determined as previously described [39]. Briefly, SS2 cultures were incubated in THB media until mid-exponential phase $\left(\mathrm{OD}_{600 \mathrm{~nm}} \approx 0.8\right)$. For $\mathrm{H}_{2} \mathrm{O}_{2}$ challenge, bacterial cells were prepared similarly, and then incubated in THB containing $58.8 \mathrm{mmol} / \mathrm{L} \mathrm{H}_{2} \mathrm{O}_{2}$ for $1 \mathrm{~h}, 2 \mathrm{~h}, 3 \mathrm{~h}$ or $4 \mathrm{~h}$. After exponentially reasonable dilution, $10 \mu \mathrm{L}$ of the dilution was spread on THA medium, incubated at $37^{\circ} \mathrm{C}$ for $24 \mathrm{~h}$ and counted, the bacterial concentration was calculated, and the survival rate was calculated.

\section{Stress -related gene detection by Quantitative RT-PCR (qRT -PCR)}

The qRT-PCR method was used to detect the expression differences of the four strains (HA9801, $\Delta l u x S$, C $\Delta l u x S$, $+\operatorname{lu} x S)$ under stress conditions. With reference to the results (Figs. 3, 4 and 5) of the above three stress tests, we chose to perform the qRT-PCR test under conditions where the stress phenotypes are extremely different. In the acid stress test, select the conditions of culturing for $12 \mathrm{~h}$ or $24 \mathrm{~h}$ at $\mathrm{pH}=5,7$; in the iron stress test, select the conditions of culturing for $6 \mathrm{~h}$ or $12 \mathrm{~h}$ when 0.1 $\mathrm{mmol} / \mathrm{L} \mathrm{Fe}\left(\mathrm{Fe}^{2+}\right.$ or $\left.\mathrm{Fe}^{3+}\right)$ is added to the iron-restricted medium; In the oxidative stress, choose the conditions of $1 \mathrm{~h}$ or $2 \mathrm{~h}$. The test procedures of total RNA extraction, reverse transcription, and fluorescence quantitative PCR are the same as those in "Validation of mRNA-Seq by qRT-PCR " above. Select 6 genes related to stress and two genes related to bacterial morphology, and use $16 \mathrm{~S}$ rRNA as an internal reference to verify the original data. Table S4 lists all primers.

\section{Statistical analysis}

The Graphad Prism 8.0 software was used to perform statistical analyses for all data. All data points for the experiments, performed in triplicate, were analyzed using the single factor analysis of variance (One-Way ANOVA), where $P<0.05$ was considered to be statistically significant.

\section{Supplementary Information}

The online version contains supplementary material available at https://doi. org/10.1186/s12866-021-02170-w.

Additional file 1: Table S1. Transcriptome up-regulated genes and their expression values.

Additional file 2: Table S2. Transcriptome down-regulated genes and their expression values.

Additional file 3: Table S3. Primers used for the quantitative RT-PCR analysis.

Additional file 4: Table S4. Primers used for the quantitative RT-PCR analysis.

Additional file 5: Figure S1. Scanning electron microscopy image of the S. suis biofilms. A: wild-type strain HA9801; B: mutant strain $\triangle$ luxS; C: complemented strain $C \Delta / U X S$ and; D:overexpression strain luxS+. SEM image showing a three-dimensional structure of the biofilm extending vertically from the surface of the membrane. Original magnification was $\times 5000$. Scale: $1 \mu \mathrm{m}$.

Additional file 6: Figure S2. The growth curve of SS2 wild-type strain HA9801, mutant strain $\Delta /$ uxS, complemented strain $C \Delta /$ uxS and overexpression strain $/ \mathrm{UxS}+$ at $37^{\circ} \mathrm{C}$. Growth was assessed by determination of $\mathrm{OD}_{600 \mathrm{~nm}}$ values at the time points indicated. Each time point represents three independent tests.

Additional file 7: Figure S3. Detection of six genes expression profiles by qRT-PCR.

Additional file 8: Figure S4. Relative expression of environmental fitness genes by S. suis HA9801, $\Delta /$ uxS, C $\Delta /$ uxS and luxS+ strains. The figure shows that the gene expression level in the HA9801 strain is 100\%, and the gene expression in the $\Delta / U \times S, C \Delta /$ uxS and luxS+ strains were the relative to expression in the HA9801 strain genes. Data from three independent assays are expressed as mean \pm SD. *, significantly different at $p<0.05$; ${ }^{* *}$, significantly different at $p<0.01 ;{ }^{* *}$, significantly different at $p<0.001$.

\section{Acknowledgements}

We acknowledge the help and wish to thank the dean, professors, and students of College of Animal Science and Technology for their constant support and cooperation.

Authors' contributions

Conceived and designed the experiments: YW and SHW. Performed the experiments: YXW, LY, QYF and JPL. Analyzed the data: LY, LYS, SHW, HZ Contributed reagents/materials/analysis tools: YBD, LYS, LY and JPL. Wrote the paper: YXW, PJL, SHW and YW. The author(S) read and approved the final manuscript. The authors read and approved the final manuscript.

\section{Funding}

This work was supported by the National Natural Science Foundation of China (31902309, 31772761), Young Teacher Foundation of Luoyang Normal University (2018XJGGJS-13), New Agricultural Research and Practice Reform Project of henan province (2020JGLX136) and Shanghai Pujiang Program (2019PJD057).

Availability of data and materials

All data generated or analyzed during this study are included in this published article and its supplementary information files. 


\section{Declarations}

\section{Ethics approval and consent to participate}

Not applicable.

\section{Consent for publication}

Not applicable.

\section{Competing interests}

The authors declare that they have no competing interests.

\section{Author details}

${ }^{1}$ College of Animal Science and Technology, Henan University of Science and Technology, Luoyang, China. ${ }^{2}$ Key Laboratory of Molecular Pathogen and Immunology of Animal of Luoyang, Luoyang, China. ${ }^{3}$ China Animal Health and Epidemiology Center, Qingdao, China. ${ }^{4}$ College of Life Science, Luoyang Normal University, Luoyang, China. ${ }^{5}$ Shanghai Veterinary Research Institute, Chinese Academy of Agricultural Sciences, Shanghai, China.

\section{Received: 14 October 2020 Accepted: 31 March 2021}

\section{Published online: 13 April 2021}

\section{References}

1. Wang $Y$, Yi L, Zhang Z, Fan H, Cheng X, Lu C. Overexpression of luxS cannot increase autoinducer-2 production, only affect the growth and biofilm formation in Streptococcus suis. Sci World J. 2013:2013:924276.

2. Wang Y, Zhang W, Wu Z, Zhu X, Lu C. Functional analysis of luxS in Streptococcus suis reveals a key role in biofilm formation and virulence. Vet Microbiol. 2011;152(1-2):151-60. https://doi.org/10.1016/j.vetmic.2011.04.029.

3. Abd El-Aziz NK, Abd El-Hamid Ml, El-Naenaeey EY. A complex hierarchical quorum-sensing circuitry modulates phenazine gene expression in Pseudomonas aeruginosa. J Infect Dev Ctries. 2018;11(12):919-25. https:// doi.org/10.3855/jidc.8775.

4. Liu B, Yi L, Li J, Wang Y, Mao C, Wang Y. Autoinducer-2 influences tetracycline resistance in Streptococcus suis by regulating the tet(M) gene via transposon Tn916. Res Vet Sci. 2020;128:269-74. https://doi.org/10.1016/j. rvsc.2019.12.007

5. Wang Y, Liu B, Grenier D, Yi L. Regulatory Mechanisms of the LuxS/AI-2 System and Bacterial Resistance. Antimicrob Agents Chemother. 2019;63(10): e01186-19. https://doi.org/10.1128/AAC.01186-19.

6. Wang Y, Liu B, Li J, Gong S, Dong X, Mao C, et al. LuxS/Al-2 system is involved in fluoroquinolones susceptibility in Streptococcus suis through overexpression of efflux pump SatAB. Vet Microbiol. 2019;233:154-8. https:// doi.org/10.1016/j.vetmic.2019.05.006.

7. Wang Y, Yi L, Zhang F, Qiu X, Tan L, Yu S, et al. Identification of genes involved in mycoplasma gallisepticum biofilm formation using mini-Tn4001SGM transposon mutagenesis. Vet Microbiol. 2017;198:17-22. https://doi org/10.1016/j.vetmic.2016.11.021.

8. Wang Y, Wang Y, Liu B, Wang S, Li J, Gong S, et al. pdh modulate virulence through reducing stress tolerance and biofilm formation of Streptococcus suis serotype 2. Virulence. 2019;10(1):588-99. https://doi.org/10.1080/21 505594.2019.1631661.

9. Liu L, Wu R, Zhang J, Li P. Overexpression of luxS promotes stress resistance and biofilm formation of Lactobacillus paraplantarum L-ZS9 by regulating the expression of multiple genes. Front Microbiol. 2018;9:2628. https://doi. org/10.3389/fmicb.2018.02628.

10. Wang $Y$, Wang $Y$, Sun L, Grenier D, Yi L. The LuxS/AI-2 system of Streptococcus suis. Appl Microbiol Biotechnol. 2018;102(17):7231-8. https:// doi.org/10.1007/s00253-018-9170-7.

11. Gregory GJ, Morreale DP, Boyd EF. CosR Is a Global Regulator of the Osmotic Stress Response with Widespread Distribution among Bacteria. Appl Environ Microbiol. 2020;86(10)

12. Lin L, Li T, Dai S, Yu J, Chen X, Wang L, et al. Autoinducer-2 signaling is involved in regulation of stress-related genes of Deinococcus radiodurans Arch Microbiol. 2016;198(1):43-51. https://doi.org/10.1007/s00203-015-11637.

13. Park H, Lee K, Yeo S, Shin H, Holzapfel WH. Autoinducer-2 quorum sensing influences viability of Escherichia coli O157:H7 under osmotic and in vitro gastrointestinal stress conditions. Front Microbiol. 2017:8:1077.

14. Song XD, Liu CJ, Huang SH, Li XR, Yang E, Luo YY. Cloning, expression and characterization of two S-ribosylhomocysteine lyases from Lactobacillus plantarum YM-4-3: implication of conserved and divergent roles in quorum sensing. Protein Expr Purif. 2018;145:32-8. https://doi.org/10.1016/j.pep.201 7.12.013.

15. Sporing I, Felgner S, Preusse M, Eckweiler D, Rohde M, Haussler S, et al. Regulation of Flagellum Biosynthesis in Response to Cell Envelope Stress in Salmonella enterica Serovar Typhimurium. MBio. 2018;9(3).

16. Hathroubi S, Zerebinski J, Ottemann KM. Helicobacter pylori Biofilm Involves a Multigene Stress-Biased Response, Including a Structural Role for Flagella. MBio. 2018;9(5)

17. Park HMS, Lee KMS, Yeo SMS, Shin HN. Autoinducer-2 quorum sensing influences viability ofEscherichia coliO157:H7 under osmotic andln VitroGastrointestinal stress conditions. Front Microbiol. 2017;8. https://doi. org/10.3389/fmicb.2017.01077.

18. Arnold WK, Savage CR, Antonicello AD, Stevenson B. Apparent role for Borrelia burgdorferi LuxS during mammalian infection. Infect Immun. 2015; 83(4):1347-53. https://doi.org/10.1128/IAl.00032-15

19. Yi L, Wang $Y$, Ma Z, Lin $H, X u B$, Grenier D, et al. Identification and characterization of a Streptococcus equi ssp zooepidemicus immunogenic GroEL protein involved in biofilm formation. Vet Res. 2016;47:50

20. Wang Y, Yi L, Wang Y, Wang Y, Cai Y, Zhao W, et al. Isolation, phylogenetic group, drug resistance, biofilm formation, and adherence genes of Escherichia coli from poultry in Central China. Poult Sci. 2016;95(12):2895901. https://doi.org/10.3382/ps/pew252

21. Zhang L, Li S, Liu X, Wang Z, Jiang M, Wang R, et al. Sensing of autoinducer-2 by functionally distinct receptors in prokaryotes. Nat Commun. 2020;11(1):5371. https://doi.org/10.1038/s41467-020-19243-5.

22. Zhang M, Sun K, Sun L. Regulation of autoinducer 2 production and luxS expression in a pathogenic Edwardsiella tarda strain. Microbiology. 2008; 154(7):2060-9. https://doi.org/10.1099/mic.0.2008/017343-0.

23. Van HR, Moons $\mathrm{P}$, Jansen A, Vanoirbeek K, Michiels CW. Isolation and functional analysis of luxS in Serratia plymuthica RVH1. FEMS Microbiol Lett. 2006;262(2):201-9.

24. Cao M, Feng Y, Wang C, Zheng F, Li M, Liao H, et al. Functional definition of LuxS, an autoinducer-2 (Al-2) synthase and its role in full virulence of Streptococcus suis serotype 2. J Microbiol. 2011;49(6):1000-11. https://doi. org/10.1007/s12275-011-1523-1

25. Zhang S, He D, Yang Y, Lin S, Zhang M, Dai S, et al. Comparative proteomics reveal distinct chaperone-client interactions in supporting bacterial acid resistance. Proc Natl Acad Sci U S A. 2016;113(39):10872-7. https://doi.org/10.1073/pnas.1606360113.

26. Wen ZT, Burne RA. LuxS-mediated signaling in Streptococcus mutans is involved in regulation of acid and oxidative stress tolerance and biofilm formation. J Bacteriol. 2004;186(9):2682-91. https://doi.org/10.1128/JB.186.9.2 682-2691.2004.

27. Li L, Xu Z, Zhou Y, Li T, Sun L, Chen H, et al. Analysis on Actinobacillus pleuropneumoniae LuxS regulated genes reveals pleiotropic roles of LuxS/ Al-2 on biofilm formation, adhesion ability and iron metabolism. Microb Pathog. 2011;50(6):293-302. https://doi.org/10.1016/j.micpath.2011.02.002.

28. van der Vinne AN, Lo RY, Shewen PE. Construction and analysis of a Mannheimia haemolytica A1 luxS mutant. Vet Microbiol. 2005;110(1-2):5366. https://doi.org/10.1016/j.vetmic.2005.06.011.

29. Trappetti C, Potter AJ, Paton AW, Oggioni MR, Paton JC. LuxS mediates Irondependent biofilm formation, competence, and fratricide in Streptococcus pneumoniae. Infect Immun. 2011;79(11):4550-8. https://doi.org/10.1128/AI.05644-11.

30. Yu J, Madsen ML, Carruthers MD, Phillips GJ, Kavanaugh JS, Boyd JM, et al. Analysis of Autoinducer-2 quorum sensing in Yersinia pestis. Infect Immun. 2013;81(11):4053-62. https://doi.org/10.1128/IAl.00880-13.

31. Yuan $L$, Hillman JD, Progulskefox A. Microarray analysis of quorum-sensingregulated genes in Porphyromonas gingivalis. Infect Immun. 2005;73(7): 4146-54. https://doi.org/10.1128/IAl.73.7.4146-4154.2005.

32. Zheng C, Xu J, Li J, Hu L, Xia J, Fan J, et al. Two Spx regulators modulate stress tolerance and virulence in Streptococcus suis serotype 2. PLoS One. 2014;9(9):e108197. https://doi.org/10.1371/journal.pone.0108197.

33. Kajfasz JK, Rivera-Ramos I, Scott-Anne K, Gregoire S, Abranches J, Lemos JA, et al. Transcription of Oxidative Stress Genes Is Directly Activated by SpxA1 and, to a Lesser Extent, by SpxA2 in Streptococcus mutans. J Bacteriol. 2015; 197(13):2160-70. https://doi.org/10.1128/JB.00118-15.

34. Yi L, Li J, Fan Q, Mao C, Jin M, Liu Y, et al. The otc gene of Streptococcus suis plays an important role in biofilm formation, adhesion, and virulence in a murine model. Vet Microbiol. 2020;251:108925. https://doi.org/10.1016/j. vetmic.2020.108925 
35. Gong X, Zhuge Y, Ding C, Zheng F, Guo X, Zhang Q, et al. A novel small RNA contributes to restrain cellular chain length and anti-phagocytic ability in Streptococcus suis 2. Microb Pathog. 2019;137:103730. https://doi.org/1 0.1016/j.micpath.2019.103730.

36. Galperin MY, Makarova KS, Wolf YI, Koonin EV. Expanded microbial genome coverage and improved protein family annotation in the COG database. Nucleic Acids Res. 2014;D1:D1.

37. Hlaing MM, Wood BR, McNaughton D, Rood Jl, Fox EM, Augustin MA. Vibrational spectroscopy combined with transcriptomic analysis for investigation of bacterial responses towards acid stress. Appl Microbiol Biotechnol. 2018;102(1):333-43. https://doi.org/10.1007/s00253-017-8561-5.

38. Lanigan N, Bottacini F, Casey PG, O'Connell Motherway M, van Sinderen D. Genome-wide search for genes required for Bifidobacterial growth under Iron-limitation. Front Microbiol. 2017;8:964. https://doi.org/10.3389/fmicb.201 7.00964.

39. Wen ZT, Nguyen AH, Bitoun JP, Abranches J, Baker HV, Burne RA. Transcriptome analysis of LuxS-deficient Streptococcus mutans grown in biofilms. Oral Microbiol Immunol. 2011;26(1):2-18. https://doi.org/10.1111/j.2 041-1014.2010.00581.x

\section{Publisher's Note}

Springer Nature remains neutral with regard to jurisdictional claims in published maps and institutional affiliations.

Ready to submit your research? Choose BMC and benefit from:

- fast, convenient online submission

- thorough peer review by experienced researchers in your field

- rapid publication on acceptance

- support for research data, including large and complex data types

- gold Open Access which fosters wider collaboration and increased citations

- maximum visibility for your research: over $100 \mathrm{M}$ website views per year

At $\mathrm{BMC}$, research is always in progress.

Learn more biomedcentral.com/submissions 